\title{
CORRELATIONS AND NEURAL NETWORKS AS MODELS FOR THE LOCAL HEAT TRANSFER COEFFICIENT ON CONDENSATION FOR R1234YF IN Ø 0.96MM DUCTS
}

\author{
R. P. Mendes ${ }^{\mathrm{a}}$, ABSTRACT \\ J. G. Pabon ${ }^{\mathrm{b}}$, \\ D. L. F. Pottie ${ }^{a}$, \\ Due to global warming considerations, the European Union has banned the \\ use of refrigerants with a GWP greater than 150 in new passenger cars (air- \\ conditioning systems) and 750 for fluids used in residential heat exchangers \\ starting on January 1, 2017 (E. UNION, 2006). In this sense, the R1234yf \\ was developed which consists of a hydrofluorolefin derived from alkenes \\ and commercialized with the name of Opteon YF. Given the need for \\ research related to the use of this fluid, this work has the objective of \\ comparing the data of the local heat transfer coefficient in condensation \\ extracted from the work of Del Col et al. (2010) for flow in a mini channel \\ of $0.96 \mathrm{~mm}$ internal diameter, with mass flux of 200, 300, 400, 600, 800 and \\ $1000 \mathrm{~kg} \cdot\left(\mathrm{m}^{2} \cdot \mathrm{s}\right)^{-1}$ at saturation temperature of $40^{\circ} \mathrm{C}$ with ten different \\ correlations from literature as well as one neural network. It is verified that \\ among the correlations analyzed the one which best suited the experimental \\ data was presented by Cavallini and Zecchin (1974), with MRD, MARD, \\ and Accuracy values equal to $5.42 \%, 7.81 \%$, and $96.96 \%$, respectively. The \\ neural network used as a prediction model presents values of MRD, \\ MARD, and Accuracy equals to $2.53 \%, 3.66 \%$, and $100 \%$, respectively. \\ ramondepaoli@yahoo.com.br \\ dpottie@gmail.com \\ leo.vsm@hotmail.com \\ luizm@demec.ufmg.br \\ buniversidade Federal de Itajubá \\ Av. BPS, 1303 \\ CEP. 37500-015, Itajubá, Minas Gerais, Brasil \\ jjgp@unifei.edu.br \\ Received: May 10, 2020 \\ Revised: Jul 16, 2020 \\ Accepted: Mar 01,2021 \\ Keywords: condensation, R1234yf, heat transfer coefficient
}

\section{NOMENCLATURE}

b Activation factors

Bo Bond Number

$\mathrm{c}_{\mathrm{p}} \quad$ Specific heat, $\mathrm{J} \cdot\left(\mathrm{kg} \cdot{ }^{\circ} \mathrm{C}\right)^{-1}$

D Diameter, $\mathrm{m}^{2}$

$f(n) \quad$ Activation function

Fr* Froud Number

G Mass flux, $\mathrm{kg} \cdot\left(\mathrm{m}^{2} \cdot \mathrm{s}\right)^{-1}$

Ga Galileo Number

g Gravity, $\mathrm{m} \cdot \mathrm{s}^{-2}$

h Enthalpy, $\mathrm{kJ} / \mathrm{kg}$

HTC Heat Transfer Coefficient, $\mathrm{W} \cdot\left(\mathrm{m}^{2} \cdot \mathrm{K}\right)^{-1}$

Ja Jakob parameter

$\mathrm{J}_{\mathrm{g}} \quad$ Wallis parameter

$\mathrm{J}_{\mathrm{g}}{ }^{\mathrm{t}} \quad$ Wallis parameter adapted

$\mathrm{k} \quad$ Conductivity, $\mathrm{W} \cdot\left(\mathrm{m}^{2} \cdot \mathrm{K}\right)^{-1}$

$\mathrm{n} \quad$ Number of values of the studied sample

$\mathrm{Nu} \quad$ Nusselt Number

Pr Prandt Number
Re Reynolds Number

$\mathrm{T}_{\text {sat }} \quad$ Saturation temperature, ${ }^{\circ} \mathrm{C}$

$\mathrm{w}_{\mathrm{i}} \quad$ Weight Matrix

x Quality

pr $\quad$ Reduced pressure

\section{Greek symbols}

$\Delta T \quad$ Temperature Difference, $\mathrm{K}$

$\rho \quad$ Specific Mass, $\mathrm{kg} / \mathrm{m}^{3}$

$\chi_{t t} \quad$ Martinelli Parameter

$\mu \quad$ Dynamic Viscosity, $\mathrm{m}^{2} / \mathrm{s}$

$\alpha \quad$ Void fraction

$\phi \quad$ Haragushi Parameter

$\sigma \quad$ Surface Tension, $N \cdot \mathrm{m}$

$\theta \quad$ Angle between the top and bottom of the tube in the Liquid phase, rad 


\section{GWP Global Warming Potential \\ MARD Absolute relative deviation \\ MRD Relative deviation \\ ODP Ozone Depletion Potential}

\section{Subscripts}

$\begin{array}{ll}\text { b } & \text { Biphasic } \\ \text { exp } & \text { Experimental } \\ \mathrm{g} & \text { Vapor } \\ \mathrm{l} & \text { Liquid } \\ \mathrm{lg} & \text { Difference between Liquid and Vapor } \\ \text { lo } & \text { Only liquid in the tube } \\ \text { mo } & \text { Monophasic } \\ \text { pred } & \text { Predicted } \\ \text { stra } & \text { Stratified }\end{array}$

\section{INTRODUCTION}

Refrigerants are constantly being replaced throughout history. Until the 1920s, natural refrigerants were used, such as propane (R290) and ammonia (R717). However, once they have high levels of toxicity and flammability, these fluids have become unfeasible for residential applications. The second generation of refrigerants was marked by substances that presented considerable safety and durability (Calm, 2008). However, due to the presence of chlorine atoms in its molecular structure, it was discovered, in the 1970 s, that the use of these fluids depleted the Earth's ozone layer.

Because of this context, several conferences were held. In response to the Montreal Protocol (UN Environment, 1987), in the late 1980s, the use of hydrofluorocarbons (HFCs) began, which have low ODP (Ozone Depletion Potential). Among the HFC fluids, it is possible to mention the R134a, which is one of the most used until nowadays, in domestic refrigerators and freezers by vapor compression and in-vehicle air conditioning units (McLinden et al., 2014). However, even having zero ODP, such fluids have a high GWP (Global Warming Potential) and, therefore, can contribute to generating harmful climate changes to the planet due to the intensification of the greenhouse effect.

Due to Global Warming considerations, the European Union has decided to ban, since January 1, 2017, the use of refrigerants with a GWP greater than 150 in new passenger cars, as well as the use of refrigerants with a GWP greater than 750 in new fixed units (E.UNION, 2006). The search for new ecological refrigerants with zero ODP and low GWP has begun. In this context, it was produced the refrigerant R1234yf, from the family of hydrofluorolefins. This fluid has a very low GWP, zero ODP and thermodynamic properties similar to those of R134a (Tanaka et al., 2010), so, even with low flammability, its use is viable in automotive systems once these already have highly flammable fluids and in greater quantity, therefore, presenting itself as a potential operating niche. Thus, R1234yf is currently being studied as a potential replacement for R134a in automotive systems. However, more research is needed on its behavior in refrigeration systems, among them studies related to the transfer of heat in condensation, since few works have been found on this topic related to the flow of R1234yf in smooth horizontal tubes in the technical literature.

Del Col et al. (2010) studied the local heat transfer coefficient of R1234yf flowing in a duct with an internal diameter of $0.96 \mathrm{~mm}$. The refrigerant presented a heat transfer coefficient lower than that of R134a for a saturation temperature of $40^{\circ} \mathrm{C}$ in the entire range of mass flux. For the mass flux of 200 $\mathrm{kg} \cdot\left(\mathrm{m}^{2} \cdot \mathrm{s}\right)^{-1}$, the heat transfer coefficient was about $15 \%$ lower for the quality of 0.4 and $30 \%$ lower for the mass flux of $800 \mathrm{~kg} \cdot\left(\mathrm{m}^{2} \cdot \mathrm{s}\right)^{-1}$ and the quality of 0.3 quality. In his work, however, he did not analyze which heat exchange-correlation would best fit the experimental data obtained by them. Furthermore, being the experimental data in the studied diameter unique in the technical literature for condensation of the fluid echo R1234yf, it is of interest to compare them with prediction models of the condensation heat transfer coefficient.

There are correlations in the literature that act as predictive models. However, they were conceived empirically for different values of mass flux, duct diameters, and refrigerants. When they are used as a prediction model for new fluids and in nonconventional duct diameters, their results may differ significantly from experimental data. In this way, the use of neural networks as a prediction model from a set of known experimental data is widely recommended and serves as a reference when used within an operating range similar to the operating range of the data through which it was obtained. The objective of this work is to study the use of empirical correlations and neural networks as prediction models of the condensation heat transfer coefficient for the eco fluid R1234yf flowing in a mini channel of 0.96 $\mathrm{mm}$ internal diameter based on the data provided by Del Col et al. (2010) in his experimental work. In the next section, it will be presented the equations of 10 correlations of local heat transfer in condensation from the technical literature. They were generated from different databases with different operating ranges and refrigerants.

\section{CORRELATIONS FOR HEAT TRANSFER}

Ten correlations from the literature were used to analyze the heat transfer coefficient in condensation for comparison with experimental results. These methodologies are the correlations of Shah (2016), Cavallini and Zecchin (1974), Dobson and Chato (1998) and Haragushi et al. (1994), Aker (1960), Bohdal et al. (2011), Park et al. (2011), Wang et al. (2002), Huang et al. (2010) and Koyama et al. (2003). They are presented briefly in Tab. 1 and in 
Tab. 2 there are presented some parameters used on these correlations.

$$
\begin{aligned}
& M R D=\frac{1}{n} \cdot \sum_{i=1}^{n} \frac{H T C_{\text {pred }}(i)-H T C_{\text {exp }}(i)}{H T C_{\text {exp }}(i)} \\
& M A R D=\frac{1}{n} \cdot \sum_{i=1}^{n}\left|\frac{H T C_{p r e d}(i)-H T C_{\text {exp }}(i)}{H T C_{\text {exp }}(i)}\right|
\end{aligned}
$$

$$
\begin{array}{r}
\text { Percentage of data } \\
\text { ACCURACY }=100 \%-\quad \text { that has moved } \\
\text { more than } 20 \%
\end{array}
$$

Where $\mathrm{HTC}_{\text {pred }}$ is the heat transfer coefficient predicted by correlation, $\mathrm{HTC}_{\exp }$ is the heat transfer coefficient measured experimentally, and (n) is the number of values of the studied sample.

The correlations can be compared to experimental data by the relative deviations (MRD), by the absolute relative deviation (MARD), and concerning the accuracy as presented in Eqs. (1)-(3).

Table 1. Correlations for Heat Transfer in Condensation.

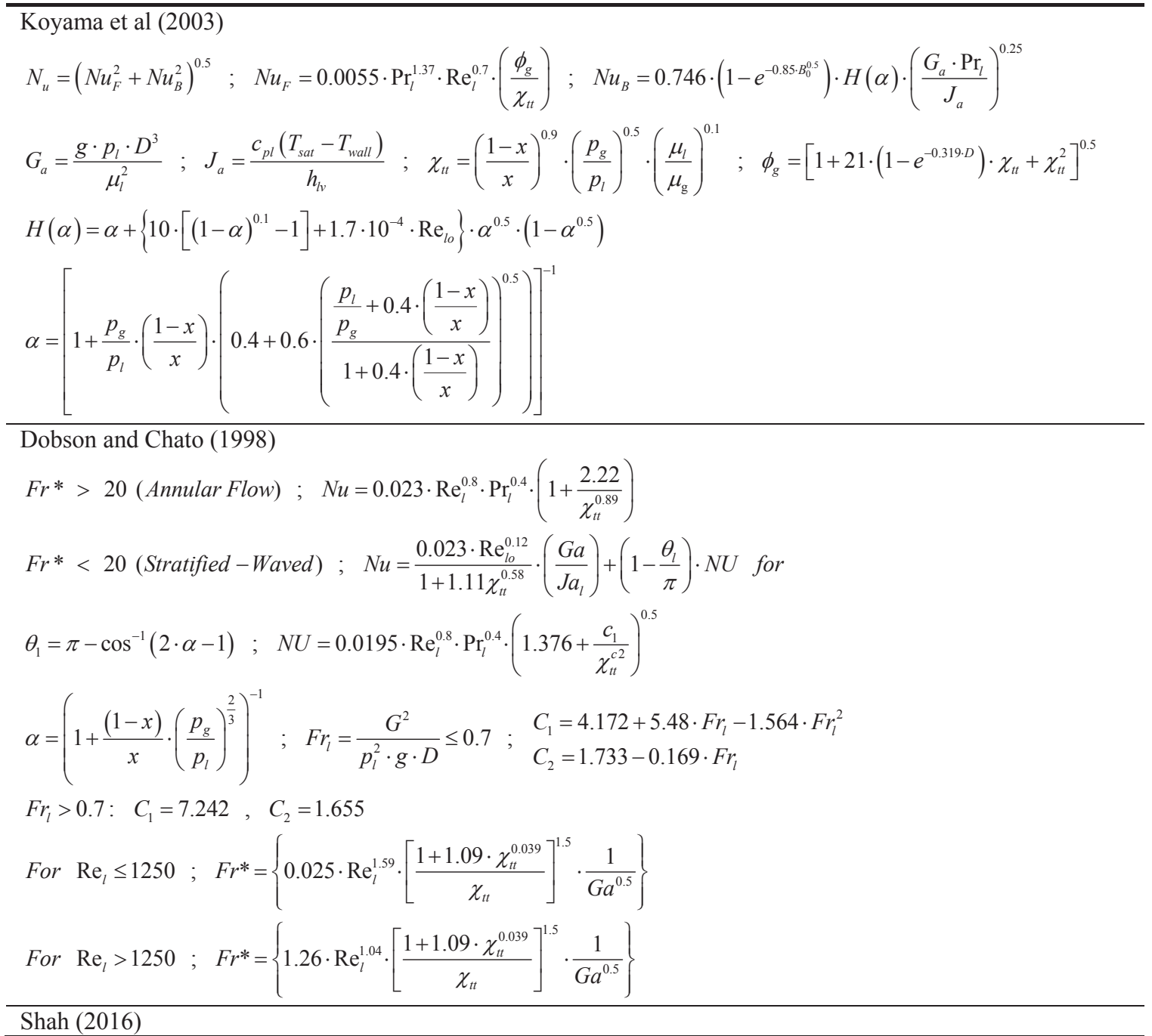




$$
\begin{aligned}
& \text { If } J_{g} \geq 0.98 \cdot(Z+0.263)^{-0.62} \quad \text { so } ; H T C_{b}=H T C_{m o} \cdot\left(\frac{\mu_{f}}{14 \cdot \mu_{g}}\right)^{n}\left[(1-x)^{0.8}+\frac{3.8 \cdot x^{0.76} \cdot(1-x)^{0.04}}{p_{r}^{0.38}}\right] \\
& \text { If } J_{g} \leq 0.95 \cdot\left(1.254+2.27 \cdot Z^{1.249}\right)^{-1} \quad \text { so } ; H T C_{b}=1.32 \cdot \operatorname{Re}_{l o}^{-\frac{1}{3}} \cdot\left[\frac{p_{l} \cdot\left(p_{l}-p_{g}\right) \cdot g \cdot k_{f}^{3}}{\mu_{f}{ }^{2}}\right]^{\frac{1}{3}} \\
& \text { If } 0.98 \cdot(Z+0.263)^{-0.62}<J_{g} \leq 0.95 \cdot\left(1.254+2.27 \cdot Z^{1.249}\right)^{-1} \quad \text { so } \\
& H_{T C_{b}}=H T C_{m o} \cdot\left(\frac{\mu_{f}}{14 \cdot \mu_{g}}\right)^{n}\left[(1-x)^{0.8}+\frac{3.8 \cdot x^{0.76} \cdot(1-x)^{0.04}}{p_{r}^{0.38}}\right]+1.32 \cdot \operatorname{Re}_{l o}^{\frac{-1}{3}}\left[\frac{p_{l} \cdot\left(p_{l}-p_{g}\right) \cdot g \cdot k_{f}^{3}}{\mu_{f}^{2}}\right]^{\frac{1}{3}} \\
& J_{g}=\frac{x \cdot G}{\left(g \cdot D \cdot p_{g} \cdot\left(p_{l}-p_{g}\right)\right)^{0.5}} ; Z=\left(\frac{1}{x}-1\right)^{0.8} \cdot p_{r}^{0.4} ; n=0.0058+0.557 \cdot \operatorname{Pr}
\end{aligned}
$$

Cavallini and Zecchin (1974)

$$
J_{g}=\frac{x \cdot G}{\left(g \cdot D \cdot p_{g} \cdot\left(p_{l}-p_{g}\right)^{0.5}\right)} ; \quad J_{G}^{T}=\left\{\left[\frac{7.5}{\left(4.3 \cdot \chi_{t t}^{1.111}+1\right)}\right]^{-3}+C T^{-3}\right\}^{-\frac{1}{3}} ; C T=1.6 \text { for hydrocarbons }
$$

$\Delta T$ independent flow regime $J_{g}>J_{G}^{T}$

$$
H C_{b}=H T C_{\text {mono }} \cdot\left[1+1.128 \cdot x^{0.817} \cdot\left(\frac{p_{l}}{p_{g}}\right)^{0.3685} \cdot\left(\frac{\mu_{l}}{\mu_{g}}\right)^{0.3685} \cdot\left(1-\frac{\mu_{g}}{\mu_{l}}\right)^{2.144} \cdot \mathrm{Pr}_{l}^{-0.1}\right]
$$

$\Delta T$ independent flow regime $J_{g} \leq J_{G}^{T}$

$$
H T C_{b}=H T C_{s t r a}+\left[h_{a} \cdot\left(\frac{J_{G}^{T}}{J_{G}}\right)^{0.8}-h_{s t r a}\right] \cdot\left(\frac{J_{G}^{T}}{J_{G}}\right) ; h_{s t r a}=0.725 \cdot\left\{1+0.741 \cdot\left[\frac{(1-x)}{x}\right]^{0.3321}\right\}^{-1} \cdot\left[\frac{k_{l}^{3} \cdot p_{l} \cdot\left(p_{l}-p_{g}\right) \cdot g \cdot h_{\mathrm{gg}}}{\mu_{l} \cdot D \cdot \Delta T}\right]+
$$

$\left(1-x^{0.087}\right) \cdot H T C_{m o} ; H T C_{m o}=0.023 \cdot \operatorname{Re}_{l o} \cdot \operatorname{Pr}^{0.4} \cdot \frac{k_{l}}{D}$

Huang et al. (2010)

$$
H T C_{b}=\left[0.0152 \cdot\left(-0.33+0.83 \cdot \operatorname{Pr}_{l}^{0.8}\right) \cdot \operatorname{Re}_{l}^{0.77} \cdot\left(\frac{\phi_{g}}{\chi_{t t}}\right)\right] \cdot \frac{k_{l}}{D} ; \phi_{g}=1+0.5 \cdot\left[\frac{G}{g \cdot D \cdot p_{g} \cdot\left(p_{l}-p_{g}\right)^{0.5}}\right]^{0.75} \cdot \chi_{t t}^{0.35}
$$

Wang et al. (2002)

$$
H T C_{b}=\left[0.0274 \cdot \operatorname{Re}_{l}^{0.6792} \cdot \operatorname{Pr}_{l} \cdot x^{0.2208} \cdot \frac{\left(1.376+8 \cdot \chi_{t t}^{1.665}\right)^{0.5}}{\chi_{t t}}\right] \cdot \frac{k_{l}}{D}
$$

Bohdal et al. (2011)

$$
H T C_{b}=\left[25.084 \cdot \operatorname{Re}_{l}^{0.258} \cdot \operatorname{Pr}_{l}^{-0.495} \cdot p r^{-0.266} \cdot\left(\frac{x}{1-x}\right)^{0.266}\right] \cdot \frac{k_{l}}{D}
$$

Arker (1960)

$$
H T C_{b}=\left[0.026 \cdot \operatorname{Pr}_{l}^{\frac{1}{3}} \cdot\left\{G \cdot\left[(1-x)+x \cdot\left(\frac{p_{l}}{p_{g}}\right)^{0.5}\right] \cdot \frac{D}{\mu_{l}}\right\}^{0.8}\right] \cdot \frac{k_{l}}{D}
$$




$$
\begin{aligned}
& N_{u}=\left(N u_{F}^{2}+N u_{B}^{2}\right)^{0.5} ; N u_{F}=0.0152 \cdot\left(1+0.6 \cdot \operatorname{Pr}_{l}^{0.8}\right) \cdot\left(\frac{\phi_{g}}{\chi_{t t}}\right) \cdot \operatorname{Re}_{l}^{0.77} ; N u_{B}=0.725 \cdot H(\alpha) \cdot\left(\frac{G a \cdot \operatorname{Pr}_{l}}{J a}\right)^{0.25} \\
& H(\alpha)=\alpha+\left\{10 \cdot\left[(1-\alpha)^{0.1}-1\right]+1.7 \cdot 10^{-4} \cdot \operatorname{Re}_{l o}\right\} \cdot \alpha^{0.5} \cdot\left(1-\alpha^{0.5}\right) ; \quad \chi_{t t}=\left(\frac{1-x}{x}\right)^{0.9} \cdot\left(\frac{p_{g}}{p_{l}}\right)^{0.5} \cdot\left(\frac{\mu_{l}}{\mu_{\mathrm{g}}}\right)^{0.1} \\
& \alpha=\left[1+\frac{p_{g}}{p_{l}} \cdot\left(\frac{1-x}{x}\right) \cdot\left(0.4+0.6 \cdot\left(\frac{\frac{p_{l}}{p_{g}}+0.4 \cdot\left(\frac{1-x}{x}\right)}{1+0.4 \cdot\left(\frac{1-x}{x}\right)}\right)^{0.5}\right]\right]^{-1} ; \phi_{g}=1+0.5 \cdot\left[\frac{G}{g \cdot D \cdot p_{g} \cdot\left(p_{l}-p_{g}\right)^{0.5}}\right]^{0.75} \cdot \chi_{t t}^{0.35} ;
\end{aligned}
$$

Park et al. (2011)

$$
\begin{aligned}
& N_{u}=\left(N u_{F}^{2}+N u_{B}^{2}\right)^{0.5} ; N u_{F}=0.0055 \cdot \operatorname{Pr}_{l}^{1.37} \cdot \operatorname{Re}_{l}^{0.7} \cdot\left(\frac{\phi_{g}}{\chi_{t t}}\right) ; N u_{B}=0.746 \cdot\left(1-e^{-0.85 \cdot B_{0}^{0.5}}\right) \cdot H(\alpha) \cdot\left(\frac{G_{a} \cdot \operatorname{Pr}_{l}}{J_{a}}\right)^{0.25} \\
& H(\alpha)=\alpha+\left\{10 \cdot\left[(1-\alpha)^{0.1}-1\right]+1.7 \cdot 10^{-4} \cdot \operatorname{Re}_{l o}\right\} \cdot \alpha^{0.5} \cdot\left(1-\alpha^{0.5}\right) ; \quad \chi_{t t}=\left(\frac{1-x}{x}\right)^{0.9} \cdot\left(\frac{p_{g}}{p_{l}}\right)^{0.5} \cdot\left(\frac{\mu_{l}}{\mu_{\mathrm{g}}}\right)^{0.1} \\
& \left.\alpha=\left[1+\frac{p_{g}}{p_{l}} \cdot\left(\frac{1-x}{x}\right) \cdot\left(0.4+0.6 \cdot\left(\frac{p_{g}}{1+0.4 \cdot\left(\frac{1-x}{x}\right)}\right)^{0.4} \cdot\left(\frac{1-x}{x}\right)\right]^{0.5}\right)\right]_{g}^{-1}=1+0.5 \cdot\left[\frac{G}{g \cdot D \cdot p_{g} \cdot\left(p_{l}-p_{g}\right)^{0.5}}\right]^{0.75} \cdot \chi_{t t}^{0.35} ;
\end{aligned}
$$

\begin{tabular}{|c|c|}
\hline Parameter & Equation \\
\hline $\begin{array}{l}\text { Reynolds number based } \\
\text { on the liquid flux }\end{array}$ & $\operatorname{Re}_{l o}=\frac{G \cdot(1-x) \cdot D}{\mu_{l}}$ \\
\hline $\begin{array}{c}\text { Reynolds number } \\
\text { considering all flux as } \\
\text { liquid }\end{array}$ & $\operatorname{Re}_{l}=\frac{G \cdot D}{\mu_{l}}$ \\
\hline Galileo Number & $G a=\frac{g \cdot \rho_{l} \cdot D^{3}}{\mu_{l}^{2}}$ \\
\hline Jakob Number & $J a=\frac{c_{p l} \cdot\left(T_{\text {sat }}-T_{\text {wall }}\right)}{h_{l v}}$ \\
\hline Wallis Parameter & $J_{g}=\frac{x \cdot G}{\left(g \cdot D \cdot \rho_{g} \cdot\left(\rho_{l}-\rho_{g}\right)\right)^{0 .}}$ \\
\hline Nusselt Number & $N u=\frac{H T C \cdot D}{k}$ \\
\hline Froud Number & $B o=\frac{D^{2} \cdot g \cdot\left(\rho_{l}-\rho_{g}\right)}{\sigma}$ \\
\hline Prandt Number & $\operatorname{Pr}_{l}=\frac{\mu \cdot c_{p}}{k_{l}}$ \\
\hline
\end{tabular}

Table 2. Dimensionless Number used in the correlations presented in Tab. 1.

\section{NEURAL NETWORKS FOR PREDICTION}

The learning process in a biological neuron consists of adjusting concentrations of chemical species in the synapses until, for a given activity, the electrical input pulses, as well as the output pulses, are considered effective in carrying out the same. The central nervous system then stores the information of the correct concentrations to be used when this procedure is performed again. An artificial neural network has different learning processes. Among these, the supervised learning in which it adjusts values (synaptic weights and activation factors) within a repetition algorithm until the desired conditions are achieved. Analogously to the adjustment of chemical concentrations in the biological system, the network compares the output informed by the user with that predicted by it until there is a minimum acceptable error between the output data predicted by the network and the output data provided experimentally.

Figure 1 shows an example of the topology of a neural network and Fig. 2 shows the network architecture extracted from the software Matlab. The process used is the supervised learning, which consists of adjusting intermediate weights $\left(\mathrm{w}_{\mathrm{i}}\right)$ and activation factors $\left(b_{i}\right)$ until their respective values provide a minimum error between the value provided by the network (input) and the value obtained experimentally (output). The network architecture consists of an input layer, which uses two neurons associated respectively with the information of quality and mass flux. In the intermediate layer, there are five neurons, this quantity is chosen through simulations with different amounts of neurons. In this layer, the sigmoidal function was used as the activation function, while in the output layer the linear function was used as the activation function. This last layer corresponds to the data of the heat transfer coefficient. 


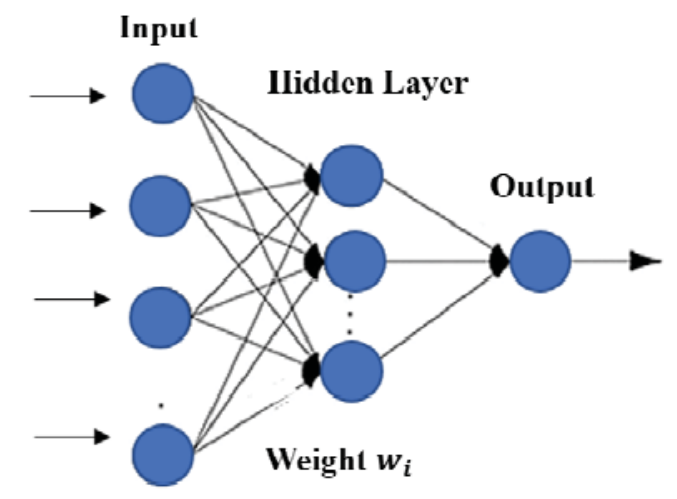

Figure 1. Topology of a Neural Network.

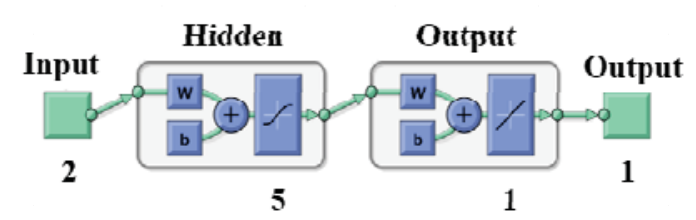

Figure 2. Topology of the Neural Network used.

$$
\begin{gathered}
f(n)=\frac{2}{\left(1+e^{-2 \cdot n}\right)}-1 \\
n=\sum_{1}^{5} w_{i} \cdot \text { Input }_{i}+b_{i}
\end{gathered}
$$

Where (w) represents the weights associated with each neuron and (b) the activation factors.

The training algorithm used was presented by More (1978). Eqs. (4) and (5) provide the expressions of sigmoidal function in each intermediate neuron.

The network topology has two input layers since that for the author's data the coefficient varies with quality and mass speed, with no data at different saturation temperatures and duct diameters. The experimental data were used to train, validate, and test the neural network, presenting in these steps correlation coefficients equal to $0.9984,0.9978$, and 0.9997 respectively. The weight matrix and the activation factors are presented in Tab. 3 .

A neural network with the weights and activation factors presented in Tab. 3 can be programmed in order to analyze the local heat transfer coefficient in condensation under the conditions studied. It has presented the average relative deviation (MRD), absolute deviation

\begin{tabular}{|c|c|c|c|c|c|c|c|}
\hline \multicolumn{7}{|c|}{ Intermediate layer } & \multirow{2}{*}{$\begin{array}{c}\text { Exit } \\
\text { Exit Neuron }\end{array}$} \\
\hline & Neuron 1 & Neuron 2 & Neuron 3 & Neuron 4 & Neuron 5 & Weights & \\
\hline W1 & -0.439642 & -3.409138 & 0.616271 & -4.992859 & -1.310514 & W3 & -1.430722 \\
\hline W2 & -0.398478 & -6.474541 & -0.519034 & -7.532807 & 1.920117 & W4 & -0.063281 \\
\hline \multirow[t]{4}{*}{ B1 } & 0.523151 & -5.881230 & -0.008969 & -4.494731 & 2.669443 & W5 & -0.036165 \\
\hline & & & & & & W6 & -0.024252 \\
\hline & & & & & & W7 & 0.303437 \\
\hline & & & & & & $\mathrm{B} 2$ & 0.084123 \\
\hline
\end{tabular}

Table 3. Weights and Activation Factors for the Neural Network trained with an internal diameter of $0.96 \mathrm{~mm}$.

(MARD), and accuracy better than the empirical correlations, as expected. These values being equal to $2.53 \%, 3.66 \%$, and $100 \%$ respectively.

\section{RESULTS AND CONCLUSIONS}

The data from Del Col et al. (2010) are added to the experimental data of other researchers to generate a larger database of the heat transfer coefficient in condensation of the R134a eco fluid. The authors provided the data for mass flux of 200, 300, 400, 600, 800 , and $1000 \mathrm{~kg} \cdot\left(\mathrm{m}^{2} \cdot \mathrm{s}\right)^{-1}$ flowing through a mini channel with $0.96 \mathrm{~mm}$ of internal diameter for a saturation temperature of $40^{\circ} \mathrm{C}$.

They observed an increase in the coefficient with the quality for all analyzed cases, which was expected, since the thickness of the liquid film on the tube wall decreases as the test section is passed through by a two-phase mixture richer in vapor, implying a lower thermal resistance of the liquid layer and, therefore, an increase in the heat transfer coefficient. Moreover, the production of more vapor implies a reduction in the specific mass of the biphasic mixture and, consequently, an increase in the vapor velocity compared to liquid velocity.

Therefore, the effects of the drag force resulting from the increase in shear stress are predominantly comparing to the effects of the force of gravity. The result is the formation of waves at the interface of the liquid film with the vapor, increasing the surface area of heat transfer. For low quality, on the other hand, there is a thick layer of liquid in contact with the tube wall and gravitational effects are predominant, implying smooth stratified flow. Thus, the thermal resistance of the layer is greater and the heat exchange area is smaller relative to the case of high quality. The result is that the condensation heat transfer coefficient shows more modest values.

The experimental data provided by them was compared with the correlations mentioned in Tab. 1, through the calculation of MRD, MARD and accuracy, to verify which one best suits the conditions of saturation temperature in $40^{\circ} \mathrm{C}$, the field of mass flux varying from 200 to $1000 \mathrm{~kg} \cdot\left(\mathrm{m}^{2} \cdot \mathrm{s}\right)-1$ and internal duct diameter of $0.96 \mathrm{~mm}$, studied by Del Col et al. (2010). 
There are presented in Fig. 3 graphs showing the deviations from the correlations of Arkers and Rosson (1960), Bohdal et al., (2011), Cavallini and Zecchin (1974) and also the deviation presented by the use of the neural network compared to the experimental ones.

Among the correlations analyzed, the one that best fitted the experimental data was the Cavallini and Zecchin (1974) correlation. It has presented values of average relative deviation, absolute deviation, and accuracy equal to $5.42 \%, 7.81 \%$, and $96.96 \%$ respectively. The MRD, MARD, and Accuracy values of the other correlations are shown in Tab. 4.

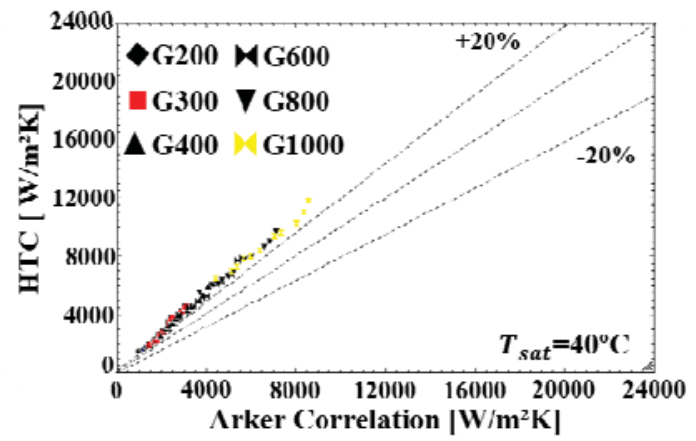

(a)

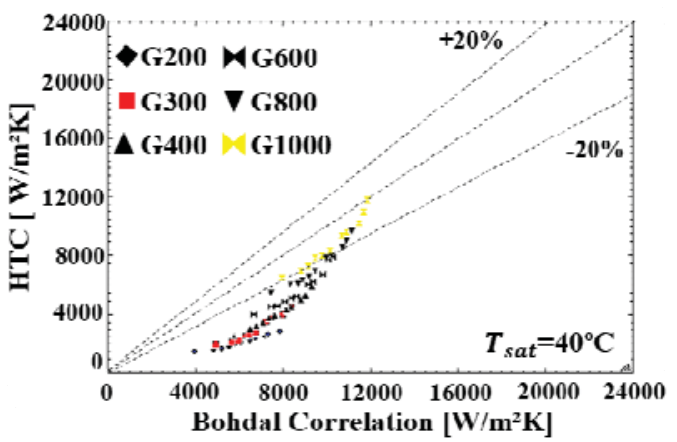

(b)

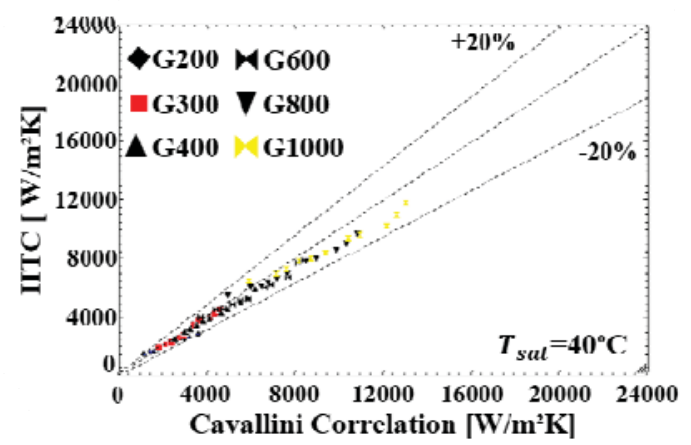

(c)

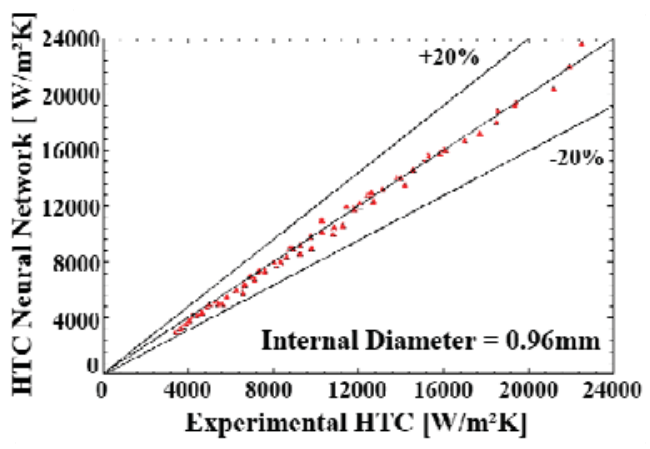

(d)

Figure 3. Graphical comparison between three correlations and the Neural Network based on the experimental data.

Table 4. MRD, MARD, and Accuracy of the correlations.

\begin{tabular}{cccc}
\hline CORRELATIONS & $\begin{array}{c}\text { MRD } \\
(\%)\end{array}$ & $\begin{array}{c}\text { MARD } \\
(\%)\end{array}$ & $\begin{array}{c}\text { ACCURACY } \\
(\%)\end{array}$ \\
\hline REDE NEURAL & 2,53 & 3,66 & 100 \\
CAVALLINI & 5,42 & 7,81 & 96,96 \\
WANG & $-0,15$ & 0,17 & 56,06 \\
KOYAMA & $-0,24$ & 0,26 & 33,33 \\
BOHDAL & 0,86 & 0,86 & 9,09 \\
CHATO & 0,36 & 0,36 & 9,09 \\
HUANG & 1,19 & 1,20 & 4,54 \\
ARKER & $-0,26$ & 0,37 & 3,03 \\
HARAGUSHI & 1,28 & 1,28 & 1,51 \\
PARK & $-0,64$ & 0,64 & 0 \\
SHAH & $-0,64$ & 0,64 & 0 \\
\hline
\end{tabular}

\section{CONCLUSIONS}

There are few experimental studies regarding the measurement of the heat transfer coefficient in condensation of the eco fluid R1234yf in smooth horizontal ducts. Among the published ones it can be mentioned the experimental data provided by Wang et al. (2012) and Yang and Nalbandian (2018). Both studied the heat transfer coefficient of R1234yf for different values of mass flux, saturation temperatures, and quality.

However, these authors studied the coefficient for ducts with an internal diameter of $4 \mathrm{~mm}$, while Del Col et al. (2010) studied for the internal diameter of $0.96 \mathrm{~mm}$. Both Wang et al. (2012) and Yang and Nalbandian (2018) presented a comparison between their experimental data with some models of prediction of the heat transfer coefficient. Del Col et al. (2010), on the other hand, did not present this comparison in his work.

Considering this context, this work analyzed the data provided by Del Col et al. (2010) comparatively with ten correlations of condensation heat transfer present in the literature and also with a Multilayer Perceptron neural network. 
The use of the neural network serves as a reference considering that, being a computational technique and having reliable experimental data, the prediction model generated by it fits very well. However, the neural network needs to be used only in conditions similar to those which generated it, once it has great deviations when used outside this range.

Figure 3 has presented the deviations graphs of $\pm 20 \%$ between the experimental data and the correlations. It is observed that the accuracy presented by the neural network, as expected, is superior to all the other three indicated.

In sequence, the values of MRD, MARD, and Accuracy were presented in Tab. 4 for all ten correlations mentioned in Tab. 1. The correlation of Cavallini and Zecchin (1974) was the one that best suited, with MRD, MARD, and Accuracy values equal to $5.42 \%, 7.81 \%$, and $96.96 \%$ respectively. Moreover, it was just slightly inferior to the model proposed by the neural network technique, which presented the values of MRD, MARD, and Accuracy in $2.53 \%, 3.66 \%$, and $100 \%$.

\section{REFERENCES}

Akers, W. W., 1960, Condensation inside a horizontal tube, Chem. Eng., Vol. 56, pp. 145-149.

Bohdal, T., Charun, H., and Sikora, M, 2011, Comparative investigations of the condensation of $\mathrm{R} 134 \mathrm{a}$ and R404A refrigerants in pipe minichannels, International Journal of Heat and Mass Transfer, Vol. 54, pp. 1963-1974.

Calm, J., 2008, The next generation of refrigerants - Historical review, considerations, and outlook, International Journal of Refrigeration, Vol. 31, No. 7, pp.1123-1133.

Cavallini, A., and Zecchin, R., 1974, A dimensionless correlation for heat transfer in forced convection condensation, in: Fifth Int. Heat Transfer Conference, Tokyo, Japan, pp. 309-313.

Del Col, D., Torresin, D., and Cavallini, A., 2010, Heat transfer and pressure drop during condensation of the low GWP refrigerant R1234yf, International Journal of Refrigeration, Vol. 33, No. 7, pp.1307-1318.

Dobson, M. K., and Chato, J. C., 1998, Condensation in smooth horizontal tubes, ASME Journal of Heat Transfer, Vol. 120, No 1, pp. 193213.

E. UNION, 2006, Directive 2006/40/ec of the european parliament and of the council of 17 may 2006 relating to emissions from, Bruxelas.

Haraguchi, H., Koyama S., and Fujii, T., 1994, Condensation of Refrigerants HCFC22, HFC134a and HCFC123 in a Horizontal Smooth Tube : 2nd Report, Proposals of Empirical Expressions for Local Heat Transfer Coefficient, Transactions of the Japan Society of Mechanical Engineers Series B, Vol. 60, No. 574, pp. 2117-2124.
Huang, X., Ding, G., Hu, H., Zhu, Y., Peng, H., Gao, Y., and Deng, B., 2010, Influence of oil on flow condensation heat transfer of R410A inside $4.18 \mathrm{~mm}$ and $1.6 \mathrm{~mm}$ inner diameter horizontal smooth tubes, International Journal of Refrigeration, Vol. 33, No. 1, pp. 158-169.

Koyama, S., Kuwahara, K., Nakashita, K., and Yamamoto, K., 2003, An experimental study on condensation of refrigerant R134a in a multi-port extruded tube, International Journal of Refrigeration, Vol. 26, No. 4, pp. 425-432.

McLinden, M. O., Kazakov, A. F., Brown, S., and Domanski P. A., 2014, A thermodynamic analysis of refrigerants: Possibilities and tradeoffs for Low-GWP refrigerants, International Journal of Refrigeration, Vol. 38, pp. 80-92.

More, J. J., 1978, The Levenberg-Marquardt algorithm: Implementation and theory, Lecture Notes in Mathematics, Vol. 630.

Park, J. E., Vakili-Farahani, F., Consolini, L., and Thome, J. R., 2011, Experimental study on condensation heat transfer in vertical minichannels for new refrigerant R1234ze(E) versus R134a and R236fa, Experimental Thermal and Fluid Science, Vol. 35, No. 3, pp. 442-454.

Shah, M. M., 2016, A correlation for heat transfer during condensation in horizontal mini/micro channels, International Journal of Refrigeration, Vol. 64, pp. 187-202.

Tanaka, K., Higashi, Y., and Akasaka, R., 2010, Measurements of the Isobaric Specific Heat Capacity and Density for HFO-1234yf in the Liquid State, Journal of Chemical \& Engineering Data, Vol. 55, No. 2, pp. 901-903.

UN Environment, 1987, Montreal Protocol on substances that Deplete the ozone Layer, in: https://www.unenvironment.org/ozonaction/ who-weare/about-montreal-protocol, Montreal.

Wang, L., Dang, C., and Hihara, E., 2012, Experimental study on condensation heat transfer and pressure drop of low GWP refrigerant HFO1234yf in a horizontal tube, International Journal of Refrigeration, Vol. 35, No. 5, pp. 1418-1429.

Wang, W. W. W., Radcliff, T. D., and Christensen, R. N., 2002, A condensation heat transfer correlation for millimeter-scale tubing with flow regime transition, Experimental Thermal and Fluid Science, Vol. 26, No. 5, pp. 473-485.

Yang, C. Y., and Nalbandian, H., 2018, Condensation heat transfer and pressure drop of refrigerants HFO-1234yf and HFC-134a in small circular tube, International Journal of Heat and Mass Transfer, Vol. 127, pp. 218-227. 